\title{
Influence of Bypass on Flow Through Plate Fin Heat Sinks
}

\author{
Rakib Hossain, J. Richard Culham and M. Michael Yovanovich \\ Microelectronics Heat Transfer Laboratory (MHTL) \\ Department of Mechanical and Mechatronics Engineering \\ University of Waterloo \\ Waterloo, Ontario, Canada N2L 3G1 \\ Corresponding author: mrhossai@engmail.uwaterloo.ca
}

\begin{abstract}
Forced air convection cooling of plate fin heat sinks is typically used as an effective means of cooling microelectronic devices because of its inherent simplicity and cost effectiveness. While the increased surface area obtained by placing plate fin heat sinks in close proximity to one another can significantly reduce the boundary resistance because of the added surface area, the added pressure drop associated with a constrained flow can lead to a decrease in inter-fin flow velocity along with a decrease in heat transfer. The ability to accurately predict the distribution of fluid flow between the fins of a heat sink and the fluid flow bypassing the heat sink is critical in the design and effective operation of heat sinks used to cool electronic components.

An analytical model for predicting air flow and pressure drop across the heat sink is developed by applying conservation of mass and momentum over the bypass regions and in the flow channels established between the fins of the heat sink. The model is applicable for the entire laminar flow range and any type of bypass (side, top or both) or fully shrouded configurations. During the development of the model, the flow is assumed to be steady, laminar, developing flow. The model is found in good agreement with the experimental data over a wide range of flow conditions, heat sink geometries and bypass configurations, typical of many applications found in microelectronics and related fields. Data published in the open literature are also used to show the flexibility of the models to simulate a variety of applications. The model is also correlated to a simple equation within $\pm 12 \%$ confidence level for easy calculation of channel velocity through the heat sink when heat sink geometry, duct geometry and flow conditions are known.
\end{abstract}

\section{Keywords}

Bypass, Compact model, Correlation, Experiment, Forced convection, Plate Fin Heat Sink, Pressure drop, Velocity.

\section{Nomenclature}

$a_{1} \quad$ Ratio of bypass area and single channel area

$A_{b} \quad$ Area of bypass $\left[\mathrm{m}^{2}\right]$

$A_{b s} \quad$ Area of side bypass $\left[\mathrm{m}^{2}\right]$

$A_{b t} \quad$ Area of top bypass $\left[\mathrm{m}^{2}\right]$

$A_{c h} \quad$ Frontal area of channel $\left[\mathrm{m}^{2}\right]$

$A_{c h 1}$ Frontal area of one channel $\left[\mathrm{m}^{2}\right]$

$A_{d} \quad$ Area of duct $\left[\mathrm{m}^{2}\right]$

$A l \quad$ Aluminium

$B \quad$ Width of heat sink $[m]$

$C B \quad$ Width of duct $[m]$

$C H \quad$ Height of duct $[m]$

$D_{h_{b s}}$ Side bypass hydraulic diameter $[\mathrm{m}]$

$D_{h_{b t}}$ Top bypass hydraulic diameter $[\mathrm{m}]$

$D_{h_{c h}}$ Channel hydraulic diameter $[\mathrm{m}]$

$f_{\text {app }} \quad$ Apparent friction factor for channel [-]

$f_{a p p_{b s}}$ Apparent friction factor for side bypass [-]

$f_{a p p_{b t}}$ Apparent friction factor for top bypass [-]

$H \quad$ Fin height $[m]$

$K_{c} \quad$ Contraction coefficient [-]

$K_{e} \quad$ Expansion coefficient [-]

$L \quad$ Length of heat sink $[m]$

$L^{*} \quad$ Dimensionless length [-]

$L_{1}^{*} \quad$ Duct dimensionless length [-]

$L_{c h}^{*} \quad$ Channel dimensionless length [-]

$L_{b s}^{*} \quad$ Side bypass dimensionless length [-]

$L_{b t}^{*} \quad$ Top bypass dimensionless length [-]

$N \quad$ Number of fins [-]

$P_{1} \quad$ Channel inlet pressure $\left[\mathrm{N} / \mathrm{m}^{2}\right]$

$P_{2} \quad$ Channel outlet pressure $\left[N / m^{2}\right]$

$P_{c} \quad$ Channel contraction pressure drop $\left[\mathrm{N} / \mathrm{m}^{2}\right]$

$P_{e} \quad$ Channel expansion pressure drop $\left[N / m^{2}\right]$

$P_{f} \quad$ Channel frictional pressure drop $\left[N / m^{2}\right]$

$P G \quad$ Plexiglas

$R e_{b s}$ Reynolds number of side bypass [-]

$R e_{b t}$ Reynolds number of top bypass [-]

$R e_{c h}$ Channel Reynolds number [-]

$R e_{d} \quad$ Duct Reynolds number [-]

$s \quad$ Fin spacing $[m]$

$t \quad$ Fin thickness $[m]$

$t_{b} \quad$ Base plate thickness $[\mathrm{m}]$

$V_{b} \quad$ Bypass velocity $[\mathrm{m} / \mathrm{s}]$

$V_{c h} \quad$ Channel velocity $[\mathrm{m} / \mathrm{s}]$

$V_{d} \quad$ Duct velocity $[\mathrm{m} / \mathrm{s}]$

\section{Greek Symbols}

$\alpha_{c h} \quad$ Channel aspect ratio [-]

$\alpha_{b s} \quad$ Side bypass aspect ratio [-]

$\alpha_{b t} \quad$ Top bypass aspect ratio [-]

$\mu \quad$ Viscosity of air $[\mathrm{kg} / \mathrm{m} \cdot \mathrm{s}]$

$\rho \quad$ Density of air $\left[\mathrm{kg} / \mathrm{m}^{3}\right]$

$\sigma \quad$ Fraction of frontal free flow area of channel [-]

$\Delta P_{b} \quad$ Pressure drop across bypass region $\left[\mathrm{N} / \mathrm{m}^{2}\right]$

$\Delta P_{b_{s}}$ Pressure drop across side bypass region $\left[\mathrm{N} / \mathrm{m}^{2}\right]$

$\Delta P_{b_{t}}$ Pressure drop across top[bypass region $\left[N / m^{2}\right]$

$\Delta P_{h s}$ Pressure drop across heat sink $\left[N / m^{2}\right]$

$\mathcal{P}_{d} \quad$ Duct perimeter $[m]$ 
$\mathcal{P}_{c h} \quad$ Channel perimeter $[m]$

$\mathcal{P}_{b s} \quad$ Perimeter of side bypass $[\mathrm{m}]$

$\mathcal{P}_{b t} \quad$ Perimeter of top bypass $[m]$

$\mathcal{P}_{f} \quad$ Perimeter of fin based on cross-sectional area of one fin $[\mathrm{m}]$

\section{Subscripts}

$\begin{array}{ll}a p p & \text { Apparent } \\ b & \text { Bypass } \\ b s & \text { Side bypass } \\ b s 1 & \text { One side of bypass } \\ b t & \text { Top bypass } \\ c & \text { Contraction } \\ c h & \text { Channel } \\ d & \text { Duct } \\ e & \text { Expansion } \\ f & \text { Friction } \\ h s & \text { Heat sink }\end{array}$

\section{Introduction}

Plate fin heat sinks are commonly used to lower the operating temperature of electronic components thereby providing conditions for reliable operation. Heat sink performance can be enhanced by increasing the convective heat transfer coefficient since the thermal conductance at the boundary is directly proportional to the product of the heat transfer coefficient and the wetted surface area. In order to estimate the magnitude of the convective heat transfer coefficient, it is necessary to have a thorough understanding of the forced convection flow provided by a fan as it distributes air through the parallel channels formed by plates fins and the baseplate as well as around the heat sink in the flow bypass region.

Heat sinks are typically attached to electronic components with sufficient clearance around the assembly to allow for free movement of an approaching air stream. A precise estimation of the air flow near the wetted regions of the heat sink is often difficult because of the number of parameters influencing the distribution of the air flow, including heat sink geometry, surrounding conditions, approaching air flow velocity, thermal conditions, etc. There are very few predictive models that allow for accuracy and easy of use despite the importance of having a good understanding of flow conditions in order to obtain accurate thermal predictions. The purpose of this paper is to provide a simplified model that allows for accurate estimation of flow conditions in parallel plate heat sinks with bypass, given relevant design information such as geometry, approach velocity and thermofluid properties.

The performance of heat sinks has been the focus of many investigations in recent years, and the subject has been treated analytically, numerically, and experimentally. Most of the work has dealt with fully shrouded heat sinks [1-8]; heat sinks in ducted flow with tip [9-15] or lateral clearance [16] or both [17-20] are also addressed by some researchers. Design of a heat sink with a clearance around it is achieved mostly through experimental and numerical methods, but both of these methods are time consuming and expensive for designing an optimized heat sink. No complete analytical model for measuring the channel velocity of a heat sink with bypass is available for use in an optimization procedure. Lee [17], and Simons and Schmidt [18] proposed a hydrodynamic model to predict the inter-fin velocity of a plate fin heat sink by applying mass and momentum balances between fins and bypass area by ignoring pressure drop (large bypass approximation) in the bypass area that can prove to be significant for small bypass clearance. They did not provide a model to estimate pressure drop inside the heat sink. Moreover, their study does not provide a clear understanding of the flow phenomena around the heat sink, and therefore, doubt remains regarding the validity of the model. Butterbaugh and Kang [19] investigated the effects of tip and lateral bypass on a heat sink with small fin spacing using compact modelling. Instead of balancing total energy (kinetic and pressure) of the fluid, they only balanced the pressure drop associated with the heat sink and bypass area in their iterative procedure to calculate the channel velocity. The predictions of their flow model were within $10 \%$ of most of their experimental data. Jonsson and Moshfegh [20] developed an empirical bypass correlation [Eq.2] based on experimental data to predict the pressure drop not the channel velocity of a plate fin heat sink under variable bypass conditions. The correlation has an agreement of $\pm 25 \%$ with their experimental data, but the correlation is limited to a certain range of duct Reynolds number, bypass to heat sink area ratio, fin spacing to height ratio and fin thickness to height ratio. Therefore, a compact model is needed to provide the necessary flow information for designing a plate fin heat sink of optimal thermal performance.

\section{Experiment}

An experimental program was conducted to provide insight for the development of an analytical model and data for evaluating the ability of the models to accurately predict the hydraulic behavior of heat sinks with bypass under a range of design conditions.

The sample heat sinks (Fig. 1) of Table 1 were used during the experimental investigation.

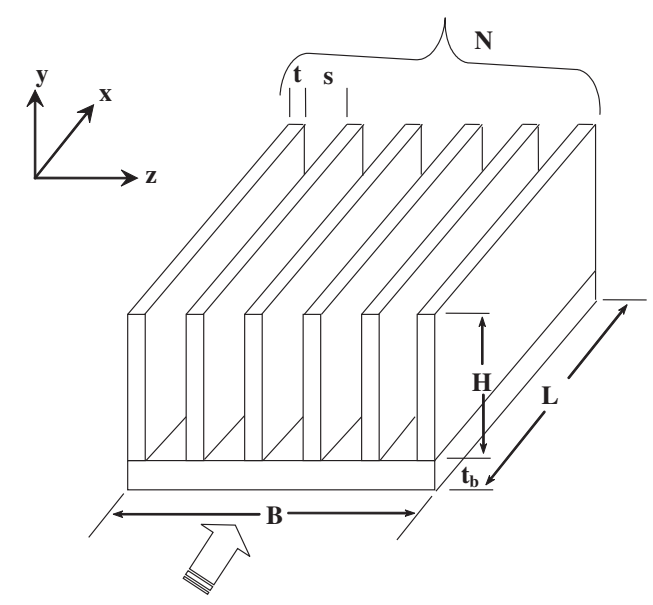

Figure 1: Geometry of a Plate Fin Heat Sink 


\begin{tabular}{|c|c|c|c|c|c|c|c|c|}
\hline HS & Mat. & $\begin{array}{c}t_{b} \\
\mathrm{~mm}\end{array}$ & $\begin{array}{c}L \\
\mathrm{~mm}\end{array}$ & $\begin{array}{c}H \\
\mathrm{~mm}\end{array}$ & $\begin{array}{c}B \\
\mathrm{~mm}\end{array}$ & $\begin{array}{c}t \\
\mathrm{~mm}\end{array}$ & $N$ & $\begin{array}{c}s \\
\mathrm{~mm}\end{array}$ \\
\hline 1 & $\mathrm{Al}$ & 8 & 102 & 50 & 96 & 1.2 & 28 & 2.25 \\
\hline 2 & $\mathrm{Al}$ & 8 & 102 & 50 & 98 & 1.2 & 18 & 4.5 \\
\hline 3 & PG & 10 & 102 & 50 & 89 & 1.5 & 30 & 1.5 \\
\hline 4 & PG & 10 & 102 & 50 & 92 & 1.5 & 21 & 3 \\
\hline 5 & PG & 10 & 102 & 50 & 93 & 3 & 16 & 3 \\
\hline
\end{tabular}

Table 1: Specification of Heat Sinks

\subsection{Setup and Procedure}

An experimental setup for measuring the pressure drop characteristics of a plate heat sink was designed and assembled. The general layout of the wind tunnel is shown in Figs. 2 and 3. The wind tunnel was fabricated from Plexiglas. The heat sink was installed at the center of the wind tunnel, and air flow was drawn into the wind tunnel through a honeycomb. The honeycomb in the chamber was used to straighten the flow inside the test section. Bypass was ensured by adjusting the side and top walls (Fig. 4) to obtain the desired clearance ratio. The duct configurations of Table 2 were used during the experiment.

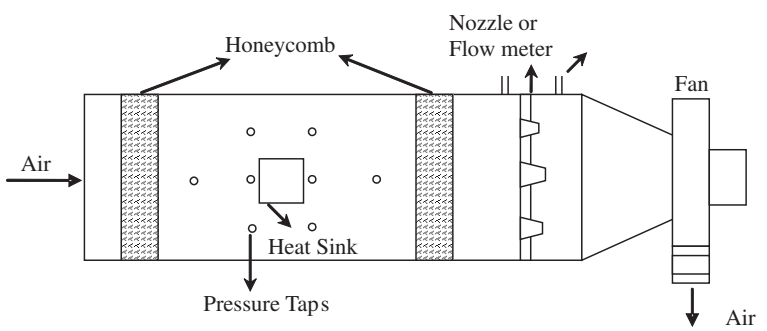

Figure 2: Top View of Wind Tunnel Configuration

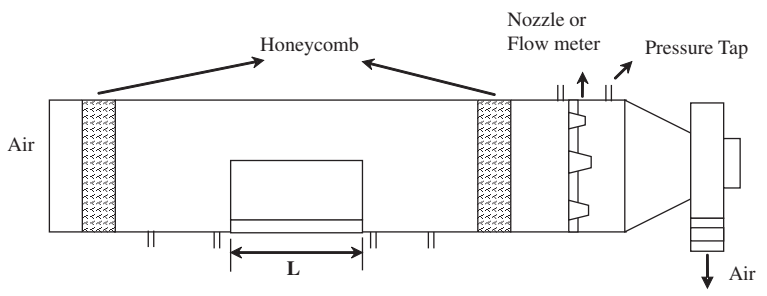

Figure 3: Side View of Wind Tunnel Configuration

Pressure taps were mounted in various locations of the duct to measure the pressure drop around the heat sink and bypass area (Fig. 2). Heat sink pressure drop was measured using two pressure taps located on the floor of the wind tunnel along the heat sink center line, and they were positioned $5 \mathrm{~mm}$ upstream and downstream of the heat sink. The air was driven by a fan and the flow rate was controlled by the frequency regulation of a motor driving the fan. Flow rates corresponding to duct velocities $1,1.5,2,2.5,3 \mathrm{~m} / \mathrm{s}$ were used during the experiment. Flow rate was measured from the nozzle (flow meter) installed at the back of the wind tunnel. The pressure drop was measured using pressure taps connected to Omega (Model-PX653) pressure transducers. Three different pressure transducers were used with full scale readings of $0.25,2$ and 10 inches $\mathrm{H}_{2} \mathrm{O}(62.3,498,2490 \mathrm{~Pa}$ respectively) depending on the prevailing pressure drop. Transducers were calibrated

Hossain, et al., Influence of Bypass on Flow Through... with a Betz water manometer prior to the experiment. The maximum error of the pressure transducers, according to the manufacturer, is $\pm 0.25 \%$ of the full scale reading. The ambient temperature in the test section was monitored using two Ttype thermocouples mounted just inside the inlet and exit of the wind tunnel. The specified accuracy of the thermocouples is $\pm 0.3^{0} \mathrm{C}$, however, when calibrating the thermocouple, an accuracy of less than $\pm 0.2^{0} \mathrm{C}$ was observed. A Labview data acquisition interface was used to record the data collected by a Keithley 2700 data logger. An average of 50 readings for each data point were recorded in order to reduce the precision error associated with the experiment.

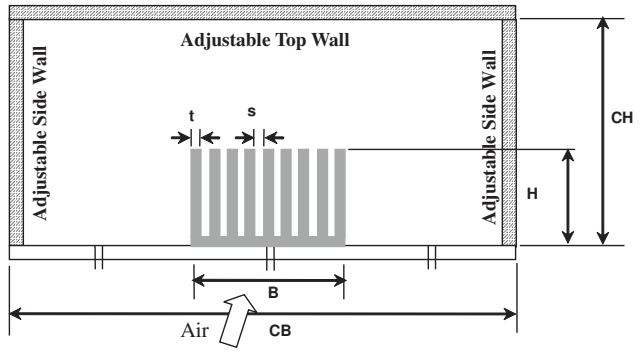

Figure 4: Front View of Wind Tunnel Configuration

\begin{tabular}{|c|c|c|c|c|c|}
\hline \multirow{2}{*}{$C B / B$} & \multicolumn{5}{|c|}{$C H / H$} \\
\cline { 2 - 6 } & 1 & 1.25 & 1.5 & 1.75 & 2 \\
\hline 1 & $\mathrm{x}$ & & & & \\
\hline 1.25 & & $\mathrm{x}$ & & & \\
\hline 1.5 & & & $\mathrm{x}$ & & \\
\hline 1.75 & & & & $\mathrm{x}$ & \\
\hline 2 & & & & & $\mathrm{x}$ \\
\hline
\end{tabular}

Table 2: Duct Configurations for Experiments (Fig. 4)

\subsection{Uncertainty of Experiments}

When estimating the uncertainty in measured and calculated quantities, both bias and precision errors were considered. These elemental errors are combined to give an overall uncertainty in a measured quantity using the root-sumsquares method. This method is expressed mathematically in Eq. 1:

$$
u_{x}= \pm\left[e_{\text {bias }}^{2}+e_{\text {precision }}^{2}\right]^{\frac{1}{2}}
$$

where $u_{x}$ represents the uncertainty in the measured quantity $x$. The estimation of bias errors $\left(e_{\text {bias }}\right)$ is based on the accuracy of the instruments [23], while the estimation of precision errors $\left(e_{\text {precision }}\right)$ is based on the statistical analysis of the data [24]. To minimize the precision uncertainty of a measurement, multiple readings were taken, typically on the order of 50.

The experimental uncertainties in $T_{a}, P_{a}, \rho_{a i r}$ and $\Delta P$ were the result of uncertainties in the experimental measurement of temperature, pressure, flow rate and uncertainties in the properties of the test fluids. The result of that analysis is summarized in Table 3. 


\begin{tabular}{|c|c|c|}
\hline \multirow{2}{*}{ Parameter } & \multicolumn{2}{|c|}{ Uncertainty } \\
\cline { 2 - 3 } & Minimum & Maximum \\
\cline { 2 - 3 } & $\%$ & $\%$ \\
\hline$T_{a}$ & \pm 0.9 & \pm 1.10 \\
\hline$P_{a}$ & \pm 0.25 & \pm 0.5 \\
\hline$\rho_{\text {air }}$ & \pm 0.45 & \pm 1.35 \\
\hline$\Delta P_{h s}$ & \pm 0.5 & \pm 2.23 \\
\hline
\end{tabular}

Table 3: Uncertainties of Experimental Parameters

\section{Model Development}

Models are developed to predict the channel velocity and pressure drop of a plate fin heat sink for fully shrouded, top bypass only, side bypass only, and both bypass based on the following assumptions:

- 2-D flow through the heat sink channel

- Channel aspect ratio $\left(\alpha_{c h} \equiv s / H\right)$ of less than 0.75

- Laminar developing flow

- Negligible leakage from the top of the heat sink

- Uniform approach velocity

- Constant fluid properties $(\rho, \mu)$

- Negligible contraction and expansion loss in bypass area

\subsection{Fully Shrouded Configuration}

For the fully shrouded configuration, $A_{b t}$ and $A_{b s}$ of Fig. 5 are zero.

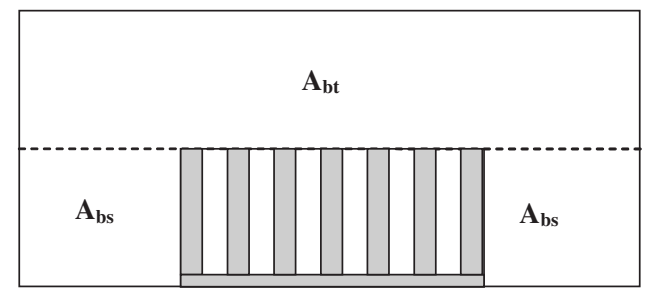

Figure 5: Arrangement of Bypass

The pressure drop across a heat sink can be expressed as:

$$
\Delta P_{h s}=P_{c}+P_{f}+P_{e}
$$

The contraction pressure drop, $P_{c}$ is :

$$
P_{c}=K_{c}\left(\frac{1}{2} \rho V_{d}^{2}\right)
$$

where the contraction loss coefficient, $K_{c}$ is correlated from the graph of Kays and London [22] for laminar flow:

$$
K_{c}=1.18+0.0015 \sigma-0.395 \sigma^{2}
$$

The expansion pressure drop, $P_{e}$ is:

$$
P_{e}=K_{e}\left(\frac{1}{2} \rho V_{c h}^{2}\right)
$$

where the expansion loss coefficient, $K_{e}$ is correlated from the graph of Kays and London [22] for laminar flow:

$$
K_{e}=1-2.76 \sigma+\sigma^{2}
$$

Hossain, et al., Influence of Bypass on Flow Through...
The frictional pressure drop, $P_{c}$ inside the channel is expressed using the Fanning friction coefficient $\left(f_{\text {app }}\right)$ as:

$$
P_{f}=\frac{2 f_{a p p} L \rho V_{c h}^{2}}{D_{h_{c h}}}
$$

Using conservation of mass, the heat sink channel velocity, $V_{c h}$ is given by:

$$
V_{c h}=\frac{V_{d}}{\sigma}
$$

where, the area ratio, $\sigma$ is defined as:

$$
\sigma=\frac{s}{s+t}
$$

For laminar hydrodynamically developing flow, the apparent friction factor, $f_{a p p}$ can be obtained from the following form of Churchill-Usagi correlation [26]:

$$
f_{\text {app }} R e_{c h}=\left[\left(\frac{3.44}{\sqrt{L_{c h}{ }^{*}}}\right)^{2}+\left(f R e_{c h}\right)^{2}\right]^{\frac{1}{2}}
$$

where $f R e_{c h}$ is the laminar fully developed friction factor.

From the combined solution of the Navier-Stokes Equation for wall shear stress and control volume analysis for one dimensional momentum flux of an arbitrary rectangular duct, $f R e_{c h}$ is reduced to the following expression [25]:

$$
f R e_{c h}=\frac{24}{1+\alpha_{c h}}
$$

After substitution of $f R e_{c h}$, Eq. 10 becomes:

$$
f_{a p p} R e_{c h}=\left[\left(\frac{3.44}{\sqrt{L_{c h}^{*}}}\right)^{2}+\left(\frac{24}{1+\alpha_{c h}}\right)^{2}\right]^{\frac{1}{2}}
$$

where

$$
\begin{aligned}
L_{c h}^{*} & =\frac{L}{R e_{c h} D_{h_{c h}}} \\
\alpha_{c h} & =\frac{s}{H} \\
R e_{c h} & =\frac{\rho V_{c h} D_{h_{c h}}}{\mu} \\
D_{h_{c h}} & =\frac{4 A_{c h}}{\mathcal{P}_{c h}} \approx 2 s \text { as } s \ll H
\end{aligned}
$$

\subsection{Top Bypass}

For a heat sink with top bypass, $A_{b s}$ of Fig. 5 is zero.

From conservation of momentum inside the control volume of the heat sink and the bypass flow area, the flow relationship for the heat sink and top bypass area is expressed as:

$$
V_{b t}^{2}-V_{c h}^{2}=\frac{2\left(\Delta P_{h s}-\Delta P_{b t}\right)}{\rho}
$$

From conservation of mass, $V_{b t}$ is given by:

$$
V_{b t}=\frac{A_{d} V_{d}-A_{c h} V_{c h}}{A_{b t}}
$$

$\Delta P_{h s}$ can obtained by using Eqs. 2 to 12 .

For laminar developing flow, $\Delta P_{b t}$ can be expressed as:

$$
\Delta P_{b t}=\frac{2 f_{a p p_{b t}} L \rho V_{b t}^{2}}{D_{h_{b t}}}
$$


$f_{a p p_{b t}}$ is obtained using the form of Eq. 12:

$$
f_{a p p_{b t}} R e_{b t}=\left[\left(\frac{3.44}{\sqrt{L_{b t}{ }^{*}}}\right)^{2}+\left(\frac{24}{1+\alpha_{b t}}\right)^{2}\right]^{\frac{1}{2}}
$$

where

$$
\begin{aligned}
L_{b t}^{*} & =\frac{L}{R e_{b t} D_{h_{b t}}} \\
\alpha_{b t} & =\frac{C H-H}{B} \\
R e_{b t} & =\frac{\rho V_{b t} D_{h_{b t}}}{\mu} \\
D_{h_{b t}} & =\frac{4 A_{b t}}{\mathcal{P}_{b t}} \\
A_{b t} & =B \times(C H-H) \\
\mathcal{P}_{b t} & =2[B+(C H-H)]
\end{aligned}
$$

\subsection{Side Bypass}

For a heat sink with side bypass, $A_{b t}$ of Fig. 5 is zero.

Using conservation of momentum inside the control volume of the heat sink and the bypass flow area, the flow relationship for the heat sink and the side bypass area is expressed as:

$$
V_{b s}^{2}-V_{c h}^{2}=\frac{2\left(\Delta P_{h s}-\Delta P_{b s}\right)}{\rho}
$$

From conservation of mass, $V_{b s}$ is given by:

$$
V_{b s}=\frac{A_{d} V_{d}-A_{c h} V_{c h}}{A_{b s}}
$$

$\Delta P_{h s}$ can be obtained using Eqs. 2 to 12.

For laminar developing flow, $\Delta P_{b s}$ can be expressed as:

$$
\Delta P_{b s}=\frac{2 f_{a p p_{b s}} L \rho V_{b s}^{2}}{D_{h_{b s}}}
$$

$f_{a p p_{b s}}$ is obtained using the form of Eq. 12:

$$
f_{a p p_{b s}} R e_{b s}=\left[\left(\frac{3.44}{\sqrt{L_{b s}^{*}}}\right)^{2}+\left(\frac{24}{1+\alpha_{b s 1}}\right)^{2}\right]^{\frac{1}{2}}
$$

where

$$
\begin{aligned}
L_{b s}^{*} & =\frac{L}{R e_{b s} D_{h_{b s 1}}} \\
\alpha_{b s 1} & =\frac{(C B-B) / 2}{H} \\
R_{b s} & =\frac{\rho V_{b s} D_{h_{b s 1}}}{\mu} \\
D_{h_{b s 1}} & =\frac{4 A_{b s 1}}{\mathcal{P}_{b s 1}} \\
A_{b s 1} & =\frac{C B-B}{2} \times H \\
\mathcal{P}_{b s 1} & =2\left[\frac{C B-B}{2}+H\right]=(C B-B)+2 H
\end{aligned}
$$

Hossain, et al., Influence of Bypass on Flow Through...

\subsection{Top and Side Bypass}

For a heat sink with both top and side bypass, both $A_{b t}$ and $A_{b s}$ of Fig. 5 exist.

From Eqs. 13 and 17, the following relationships can be obtained:

$$
\begin{aligned}
\left(V_{b t}^{2}+V_{b s}^{2}\right)-2 V_{c h}^{2} & =\frac{4 \Delta P_{h s}-2\left(\Delta P_{b t}+\Delta P_{b s}\right)}{\rho}(21) \\
V_{b s}^{2}-V_{b t}^{2} & =\frac{2\left(\Delta P_{b t}-\Delta P_{b s}\right)}{\rho} \\
A_{b t} V_{b t}+A_{b s} V_{b s} & =A_{b} V_{b} \\
A_{b} V_{b} & =A_{d} V_{d}-A_{c h} V_{c h} \\
A_{b} & =A_{d}-A_{h s} \\
A_{d} & =C B \times C H \\
A_{h s} & =N t H+(N-1) s H \\
A_{c h} & =(N-1) s H
\end{aligned}
$$

$\Delta P_{h s}, \Delta P_{b t}$ and $\Delta P_{b s}$ are obtained from Eqs. 2, 15 and 19.

The values of $V_{c h}, V_{b t}$ and $V_{b s}$ can be obtained by the simultaneous solution of Eqs. 21 - 28, 2, 15 and 19 using mathematical software such as Maple or Mathematica.

\subsection{Correlation for Channel Velocity}

The solution for the model described above can be obtained using a software simulation tool such as Maple or Mathematica. An approximation of the full solution can be obtained using a simple correlation that includes all variables (geometries, flow conditions and fluid properties). The correlation is well suited for the iterative procedure used in the parametric optimization of heat sinks.

The following correlation (Eq. 29) is developed to calculate the channel velocity $\left(V_{c h}\right)$ through the heat sink with flow bypass.

$$
\begin{aligned}
& V_{c h}=V_{d} \quad\left(\frac{s+t}{s}\right)\left[1-\left(L_{1} \times a_{1}\right)^{0.125}\right] \\
& L_{1}=\frac{L}{R e_{d} D_{h_{d}}} \\
& R e_{d}=\frac{\rho V_{d} D_{h_{d}}}{\mu} \\
& D_{h_{d}}=\frac{4 C B \times C H}{2(C B+C H)} \\
& a_{1}=\frac{A_{b}}{A_{c h_{1}}} \\
& A_{b}=C B \times C H \\
& A_{c h_{1}}=s \times H
\end{aligned}
$$

When bypass area $\left(A_{b}\right)$ becomes zero, Eq. 29 takes the form of conservation of mass for a single channel of the fully shrouded model.

$$
V_{c h}=V_{d}\left(\frac{s+t}{s}\right)
$$

23rd IEEE SEMI-THERM Symposium 
Correlated values are found to be within $\pm 12 \%$ of the model data.

\section{Result and Discussion}

The pressure drop obtained from the model for various duct configurations are compared with the experimental data of various heat sinks at duct velocities of $1,1.5,2,2.5$, and 3 $\mathrm{m} / \mathrm{s}$.

Figures 6, 7, 8 compare the model with the experimental data of the sample 1 heat sink for various side, top and combination of top and side bypass configurations. The model and experimental data are in excellent agreement for various duct velocities with an RMS difference ranging from 2.6 to $8.5 \%, 6.0$ to $9.1 \%$ and 3.6 to $8.8 \%$ respectively. The data for the other heat sink samples are also found in good agreement with the model.

Experimental data of Butterbaugh and Kang [19] are also compared with the model for their heat sink geometry and duct configurations. The results of the model show good agreement with their experimental data with overall RMS errors ranging from $6 \%$ to $9 \%$ (Fig. 9).

Figure 10 shows the velocity distribution (obtained from model) inside the heat sink of sample 1 and bypass (top and side) region for various duct velocities and one particular bypass arrangement, and found that with the increase of duct velocity, velocity through the heat sink channel increases. The plot also shows that pressure drop corresponding to the channel velocity obtained from the model is also in good agreement with the experimental data.

The influence of the clearance region on channel velocity obtained from the model are shown in Fig. 10, and the corresponding pressure drop is found in good agreement with the experimental data. The RMS error varies between $3.9 \%$ and $8.6 \%$.

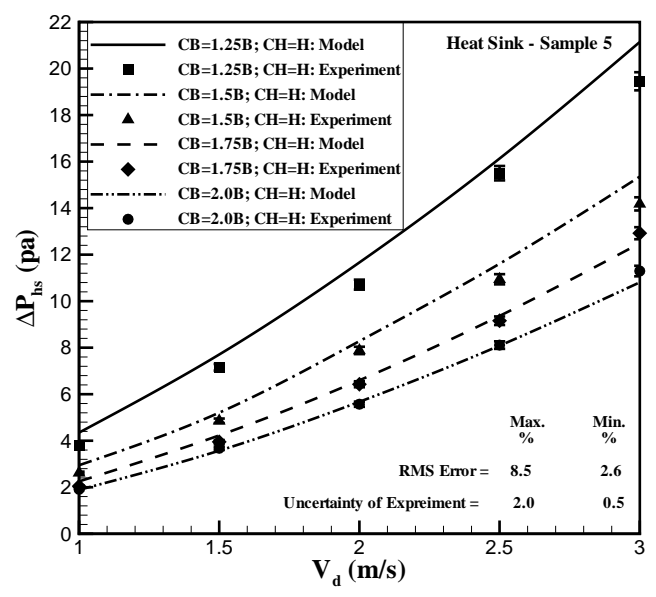

Figure 6: Validation of Side Bypass Model

\section{Conclusion}

This research work presents the development of an analytical model for fluid flow through a heat sink by applying

Hossain, et al., Influence of Bypass on Flow Through...

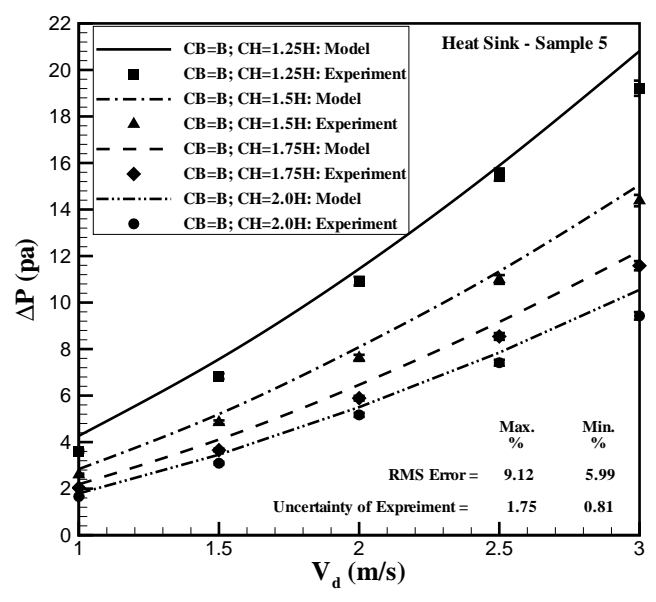

Figure 7: Validation of Top Bypass Model

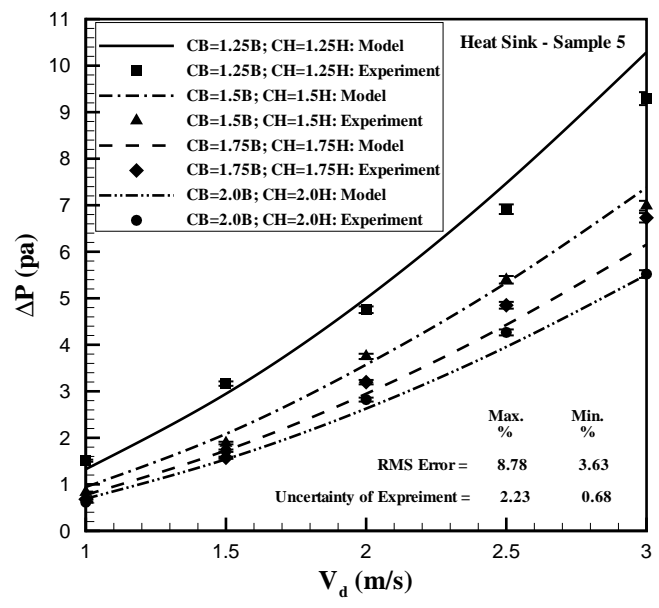

Figure 8: Validation of Combined Top and Side Bypass Model

a control volume analysis for mass and momentum balance between heat sink and bypass area in order to accurately predict the air flow through the heat sink. The control volume analysis incorporates the flow and frictional drag associated with the heat sink and bypass area for laminar developing flow. The model was validated with experimental data for pressure drop and found to have an RMS error ranging from 2.6 to $9.1 \%$. The model was later validated with the experimental data of Butterbugh and Kang [19] using their heat sink and duct geometry, and the RMS difference was found within $9 \%$. Their experimental procedures were similar to this research study. A correlation for channel velocity was built with respect to flow conditions, heat sink and duct geometry, and the RMS error was found $\pm 12 \%$ with respect to the model data.

\section{Acknowledgement}

The authors gratefully acknowledge the financial support of the Natural Sciences and Engineering Research Council 


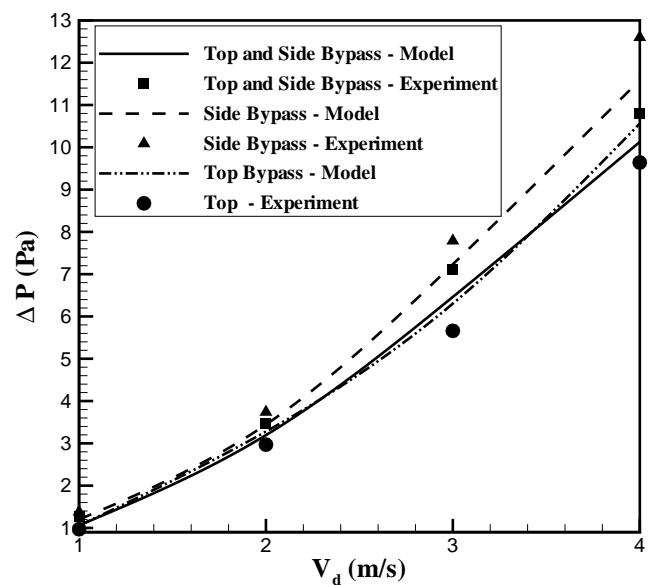

Figure 9: Validation of Model with The Experimental Data of Butterbaugh and Kang

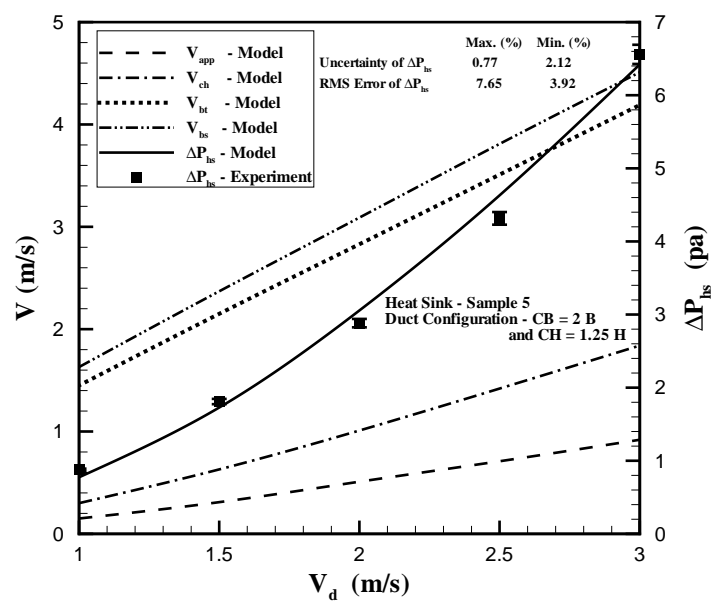

Figure 10: Velocity Distribution in Heat Sink and Bypass Region

(NSERC) of Canada for this research.

\section{References}

1. Goldberg, N., "Narrow Channel Forced Air Heat Sink," IEEE Transactions on Components, Hybrids, and Manufacturing Technology, Vol. CHMT-7, No. 1, 1984, pp. 154-159.

2. Azar, K., McLeod, R.S., and Caron, R.E., "Narrow Channel Heat Sink for Cooling of High Powered Electronics Components," Proceedings of the Eighth Annual IEEE Semiconductor Thermal Measurement and Management Symposium (SEMITHERM VIII), Austin, TX, 1992, pp. 12-19.

3. Holahan, M.F., Kang, S.S., and Bar-Cohen, A., "A Flow Stream Based Analytical Model for Design of Parallel Plate Heat Sinks," ASME Proceedings of the $31^{\text {st }}$ National Heat Transfer Conference (HTD-Vol. 329), Houston, TX, Vol. 7, 1996, pp. 63-71.

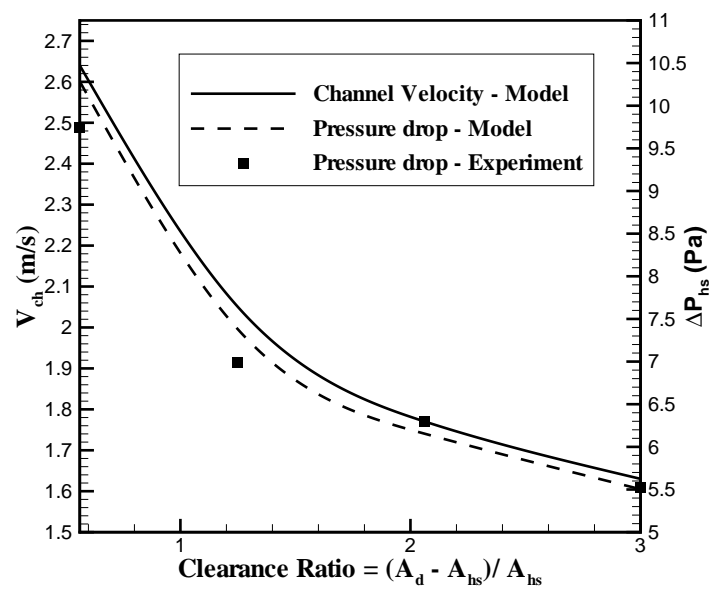

Figure 11: Influence of bypass on channel velocity $\left(V_{c h}\right)$

4. Copeland, D., "Optimization of Parallel Plate Heat Sinks for Forced Convection," Proceedings of the Sixteenth Annual IEEE Symposium on Semiconductor Thermal Measurement and Management (SEMI-THERM XVI), San Jose, CA, 2000, pp. 266-272.

5. Teertstra, P., Yovanovich, M.M., Culham, J.R., and Lemczyk, T., "Analytical Forced Convection Modelling of Plate Fin Heat Sinks," Proceedings of the Fifteenth Annual IEEE Symposium on Semiconductor Thermal Measurement and Management, San Diego, CA, 1999, pp. 34-41.

6. Saini, M., and Webb, L.R., "Validation of Models for Air Cooled Plane Fin Heat Sinks Used in Computer Cooling," Proceedings of the Eighth Intersociety Conference on Thermal and Thermomechanical Phenomena in Electronic Systems (ITHERM), 2002, pp. 244-250.

7. Narasimhan, S., and Bar-Cohen, A., "Flow and Pressure Field Characteristics in the Porous Block Compact Modelling of Parallel Plate Heat Sinks," IEEE Transactions on Components, Packaging and Manufacturing Technologies, Vol. 26, No. 1, 2003, pp. 147-157.

8. Knight, R.W., Goodling, J.S., and Gross, B.E., "Optimum Thermal Design of Air Cooled Forced Convection Finned Heat Sinks- Experimental Verification," IEEE Transactions on Components, Hybrids, and Manufacturing Technology, Vol. 15, No. 5, 1992, pp. 754-760.

9. Lee, R.S., Huang, H.C., and Chen, W.Y., "A Thermal Characteristic Study of Extruded-Type Heat Sinks in Considering Air Flow Bypass Phenomena," Proceedings of the Sixth Annual IEEE Symposium on Semiconductor Thermal and Temperature Measurement (SEMI-THERM VI), Phoenix, AZ, 1990, pp. 95102.

10. Wirtz, R.A., Chen, W., and Zhou, R., "Effect of Flow Bypass on the Performance of Longitudinal Fin Heat Sinks," ASME Journal of Electronic Packaging, Vol. 116, 1994, pp. 206-211. 
11. Sparrow, E.M., and Beckley, T.J., "Pressure Drop Characteristic for a Shrouded Longitudinal Fin Array with and without Tip Clearances," ASME Journal of Heat Transfer, Vol. 103, 1981, pp. 393-395.

12. Lau, K.S., and Mahajan, R.L., "Effects of Tip Clearance and Fin Density on the Performance of Heat Sinks for VLSI Packages," IEEE Transactions on Components, Hybrids, and Manufacturing Technology, Vol. 12, No. 4, 1989, pp. 757-765.

13. Leonard, W., Teertstra, P., and Culham, J.R., "Characterization of Heat Sink Flow Bypass in Plate Fin Heat Sinks," Proceedings of ASME International Mechanical Engineering Congress \& Exposition (IMECE2002-39556), New Orleans, Louisiana, 2002.

14. Coetzer, C.B., and Visser, J.A., "Compact Modeling of Forced Flow in Longitudinal Fin Heat Sinks with Tip Bypass," ASME Journal of Electronic Packaging, Vol. 125, 2003, pp. 319-324.

15. Min, J.Y., Jang, S.P., and Kim, S.J., "Effect of Tip Clearance on the Cooling Performance of a Microchannel Heat Sink," International Journal of Heat and Mass Transfer, Vol. 47, 2004, pp. 1099-1103.

16. Iwasaki, H., Sasaki, T., and Ishizuka, M., "Cooling Performance of Plate Fins for Multichip Modules," IEEE Transactions on Components, Packaging and Manufacturing Technology -Part A, Vol. 18, No. 3, 1995, pp. 592-595.

17. Lee, S., "Optimum Design and Selection of Heat Sinks," IEEE Transactions on Components, Packaging and Manufacturing Technologies, Vol. 18, 1995, pp. 812-817.

18. Simons, R.E., and Schmidt, R.R., "A Simple Method to Estimate Heat Sink Air Flow Bypass," Electronics Cooling, Vol.3, No. 2, 1997, pp. 36-37.

19. Butterbaugh, M.A., and Kang, S.S., "Effect of Airflow Bypass on the Performance of Heat Sinks in Electronic Cooling," ASME Advances in Electronic Packaging, Vol. EEP-10-2, 1995, pp. 843-848.

20. Jonsson, H., and Moshfegh, B., "Modeling of the Thermal and Hydraulic Performance of Plate Fin, Strip Fin, and Pin Fin Heat Sinks- Influence of Flow Bypass," IEEE Transactions on Components and Packaging Technologies, Vol. 24, No. 2, 2001, pp. 142-149.

21. Moffat, R. J., "Describing the Uncertainties in Experimental Results," Experimental Thermal and Fluid Science, Vol. 1, 1988, pp. 3-17.

22. Kays, W.M., and London, A.L., Compact Heat Exchangers, New York: McGraw-Hill, 1984.

23. Holman, J.P., Experimental Methods for Engineers, New York: McGraw-Hill, 2001.

24. Montgomery, D.C., Design and Analysis of Experiments, New York: Wiley, 2001.
25. Hossain, M.R., "Optimization of a Plate Fin Heat Sink with Flow Bypass using Entropy Generation Minimization," MASc Thesis, Department of Mechanical Engineering, University of Waterloo, Appendix A, 2006, pp. 142-146.

26. Churchil, S.W. and Usagi, R., "A General Expression for the Correlation of Rates of Transfer and Other Phenomena," AIChE Journal, Vol. 18, No. 6, 1972, pp. 1121 - 1128. 